\title{
Celestina: Documento bibliográfico (suplemento número 42)
}

Celestina: Bibliographical document (supplement number 42)

\author{
Amaranta Saguar García \\ Universidad Complutense de Madrid \\ Devid Paolini \\ The City College of New York
}

2733. ÁlVAREZ-MORENO, Raúl, «Si fructus, si flos, si duo: la tradición paratextual esópica y Celestina», Lemir 24 (2020): 345-370 [en línea, $<$ https://parnaseo.uv.es/Lemir/Revista/Revista24/13_Alvarez_Raul. pdf $>$, fecha de consulta: 23 de octubre de 2020]

Estudio que señala y analiza la posible relación entre la tradición esópica -en particular, los prólogos del primer libro de las Fábulas y la Vida de Esopo-y la obra maestra española enfocándose tanto en elementos literarios como ideológicos.

2734. BASTIANES, María, Vida escénica de "La Celestina» en España (19092019). Berlin: Peter Lang, 2020.

Este libro recorre la peculiar vida de La Celestina en las tablas españolas, desde sus inicios al comienzo del siglo xx hasta nuestros días, pasando por su difícil situación durante el franquismo. En sus páginas se dan cita los principales protagonistas de esta historia escénica: directores, adaptadores, diseñadores, actores, pero también críticos, censores e intelectuales que con sus juicios (y prejuicios) condicionaron la manera de leer un clásico en el que muchas veces se jugó la identidad cultural de España [resumen de la autora, publicado en línea en el catálogo de Peter Lang].

2735. BASTIANES, María, «La adaptación de La Celestina de Luis Escobar y Huberto Pérez de la Ossa. Un análisis formal», Celestinesca 43 (2019): 9-32 [en línea, <http://parnaseo.uv.es/Celestinesca/Celestinesca43/01_ Bastianes_Maria.pdf $>$, fecha de consulta: 23 de octubre de 2020].

Estudia la adaptación teatral de $L C$ llevada a cabo por Luis Escobar y Huberto Pérez de la Ossa en 1957, centrándose en las modificaciones formales de aquella y dejando afuera las que fueron originadas por la censura. 
2736. BIAGGINI, Olivier, "Évoquer / invoquer la ville: la construction littéraire de l'espace urbain dans le Libro de buen amor et la Célestine», e-Spania 37 (2020): s.p. [en línea, <https://doi.org/10.4000/e-spania.36143>, fecha de consulta: 29 de octubre de 2020].

La ciudad no está propiamente descrita en $L C$, sino que se sugiere a partir del recurso de la hipotiposis. Este espacio urbano así descrito está indisociablemente unido al proceso de seducción amorosa y a la figura de la medianera, por lo que la hipotiposis también afecta a la manera en la que el texto presenta la acción. En concreto, afecta a cómo se presentan los mecanismos de seducción y corrupción, hasta el punto de que los conflictos desencadenados por estos reflejan los conflictos de la ciudad.

2737. BIDWELL-STEINER, Marlen, "Celestina: Himmlische Erhöhung des Höllisch Abjekten", en Das Grenzwesen Mensch: Vormoderne Naturphilosophie und Literatur im Dialog mit Postmoderner Gendertheorie: Berlin \& Boston, De Gruyter, 2017, 267-282. *

2738. BLECUA, Alberto, "Sobre el Ms. de Palacio de La Celestina», en La Celestina: ecdotica e interpretazione, ed. Francisco Lobera Serrano. Roma: Bagatto Libri, 2010, 17-42. *

2739. BOND, Brad, "Celestina, a Tragic Musical Comedia: A New Old Bawd-way Musical», en Videoactas del I Congreso del CELPYC (4-5 de junio de 2020), ed. Enrique Fernández y Amaranta Saguar. Nueva York: CELPYC, 2020, s. p. [en línea, <https://doi.org/10.47537/ celpyc2020.02>, fecha de consulta: 26 de octubre de 2020].

Génesis y ejecución del musical sobre LC titulado Celestina, a Tragic Musical Comedia.

2740. BOTTA, Patrizia, "Mujeres celestinescas en la Roma del s. XVII (Ms. Corsini 625)", en Et era muy acuçioso en allegar el saber: studia philologica in honorem Juan Paredes, ed. Eva Muñoz Raya y Enrique Nogueras Valdivieso. Granada: Universidad de Granada, 2020, 167-180.

Breve noticia y transcripción de un poema inédito de tema celestinesco ("Dios me guarde, Dios me guarde») que se encuentra en un cancionero musical de principios del siglo XVII (Ms. Corsini 625) y que se conserva en la Accademia dei Lincei en Roma.

2741. BRIS, Juan, "Un aspecto del mito y de la leyenda clásica en La Celestina: el cabello de Melibea y el mito de Medusa», en Conuentus Classicorum: Temas y formas del Mundo Clásico, ed. Jesús de la Villa Polo et al. Madrid: Sociedad Española de Estudios Clásicos, 2017, vol. 2, 659-666. 
Análisis que se enfoca en la mención indirecta, durante la descripción de Melibea hecha por Calisto en el acto I, del mito de Médusa que arrojaría nueva luz sobre las fuentes clásicas manejadas por los autores de la obra maestra española (Ovidio a través de la recreación de Juan de Mena) y, al mismo tiempo, ayudaría a entender, de forma más coherente y completa, una de las respuestas de Sempronio — que a su vez derivaría de un pasaje clásico (Apuleyo).

2742. BRIS, Juan, «Medusa en Melibea: un aspecto iconográfico de la mitología clásica en La Celestina», en Conuentus Classicorum: Temas y formas del Mundo Clásico, ed. Jesús de la Villa Polo et al. Madrid: Sociedad Española de Estudios Clásicos, 2017, vol. 2, 667-674.

Una ampliación del tema introducido en la investigación anterior en la que se incluye, también, un estudio iconográfico que relaciona el pasaje de Ovidio, refundido por Mena y de aquí pasado a $L C$, con el Perseo de Benvenuto Cellini.

2743. BRIS, Juan, «La transmisión de varias fuentes mitológicas de las Metamorfosis y las Heroidas en La Celestina», Estudios Clásicos 4 (2018), 191-200.

Trabajo que se centra en el estudio de los mitos ovidianos presentes en $L C$, con particular referencia a la leyenda de Píramo y Tisbe (Metamorfosis IV) y Hero y Leandro (Heroidas 18 y 19).

2744. BRIS, Juan, "Las leyendas y mitos helenos en la interpolación de la Tragicomedia de Calisto y Melibea», Anuario Calderoniano 13 (2020), 21-46 [en línea, <https://recyt.fecyt.es/index.php/acal/article/view/72351>, fecha de consulta: 23 de octubre de 2020].

Estudio de las leyendas y los mitos griegos reconocibles en el llamado «auto de Centurio».

2745. CALDERÓN CALDERÓN, Manuel, "Guiomar do Porto" o leer sin perder el hilo", Celestinesca 43 (2019), pp. 33-58 [en línea, <http://parnaseo.uv.es/Celestinesca/Celestinesca43/02_Calderon_Manuel.pdf>, fecha de consulta: 23 de octubre de 2020].

Estudio del anónimo Auto de Guiomar do Porto en relación con la celestinesca.

2746. CANAVAGGIO, Jean, «La Celestina en el espejo del teatro español de los siglos XVI y XVII», en Doctos libros juntos, homenaje al profesor Ignacio Arellano Ayuso, ed. Juan Manuel Escudero Baztán y Victoriano Roncero López. Frankfurt am Main: Vervuert, 2018, 117-132 [en línea, $<$ https://doi.org/10.31819/9783954877577-007>, fecha de consulta: 23 de octubre de 2020]. 
Traducción española del original publicado en francés en Celestinesca 32 (2008), 69-84 y ya reseñado por Joseph Snow en el suplemento bibliográfico de la misma revista en 2009.

2747. CANET VALLÉS, José Luis, Estudios sobre "Celestina": de la "sotil inveción a la imprenta. Con glosas nuevamente añadidas, ed. Marta Haro Cortés, Valencia, Universitat de València, 2020.

Recopilación de trabajos de José Luis Canet sobre $L C$ con comentarios de conocidos celestinistas.

2748. CANET VALLÉS, José Luis, ed., La "Égloga de la Tragicomedia de Calisto y Melibea» de Pedro Manuel de Urrea (1513). Valencia: LEMIR Universidad de Valencia 2003 [en línea, <http://parnaseo.uv.es/Lemir/ Textos/Egloga/Index.htm>, fecha de consulta: 23 de octubre de 2020].

Edición crítica anotada de la Égloga de la Tragicomedia de Calisto y Melibea, primera imitación celestinesca y primera adaptación representable de la que conservamos el texto (anterior al Interlude of Calisto and Melebea).

2749. CARNERO, Guillermo, La caza de amor o el amor sin caza, en el huerto o la huerta de Melibea. Salamanca: SEMYR, 2017.

Estudio que se centra en la escena inicial de $L C$ con el objetivo de aclarar su ubicación que no sería ni una iglesia - como propuesto por Riquer en 1957 ( (Fernando de Rojas y el primer acto de LC») — ni una huerta o terreno abierto y rural — como señalado por Botta en 2001 ("Las ¿dos? casas de Melibea»).

2750. CARRASCO MARTÍNEZ, Sara, y Andrés MONTANER BUENO, "Promoting Reading in the Classrooms of Bachillerato. The Relationship Spaces between El Manuscrito de piedra by Luis García Jambrina and La Celestina by Fernando de Rojas", Annals of Language and Literature 3.3 (2019): 11-20 [en línea, <https://www.sryahwapublications. com/annals-of-language-and-literature/volume-3-issue-3/3>, fecha de consulta: 23 de octubre de 2020].

Propuesta didáctica para acercar a los estudiantes de primero de bachillerato a $L C$ a partir de la novela El manuscrito de piedra de Luis García Jambrina.

2751. CÁSEDA TERESA, Jesús Fernando, «Los orígenes del arcipreste de Talavera y del primer acto de La Celestina», Celestinesca 43 (2019): 5992 [en línea, <http://parnaseo.uv.es/Celestinesca/Celestinesca43/03_ Caseda_Jesus.pdf $>$, fecha de consulta: 23 de octubre de 2020].

Estudio sobre Alfonso Martínez de Toledo, a quien se ha indicado como posible autor del primer acto de $L C$. Se aporta información acerca 
de sus posibles orígenes familiares y formación y se señalan algunas coincidencias entre el Corbacho y la obra maestra española.

2752. CASTRO RODRÍGUEZ, María Luisa, "Calisto ¿personaje paródico o parodiado?», en Perspectivas y proyecciones de la literatura medieval, eds. Aurelio González y Lilian Von der Walde. México: Colegio de México, UNAM, 2017, 475-484.

Defensa de la caracterización de Calisto como amante cortés sin elementos paródicos. La distorsión burlesca del enamorado se produce porque lo vemos con los ojos realistas de los personajes bajos, quienes observan su comportamiento histriónico de enamorado cortés desde fuera, pero en realidad la forma de actuar de Calisto está acorde con las convenciones amorosas dentro de las que se mueve. La ausencia de los criados y de Celestina a partir del auto XII es lo que provoca que parezca que Calisto recupera su dignidad y le confiere rasgos trágicos.

2753. CERRÓN PUGA, María Luisa, "Celestina irreprensible. Avatares de una censura tardía», en La Celestina: ecdotica e interpretazione, ed. Francisco Lobera Serrano. Roma: Bagatto Libri, 2010, 125-158. *

2754. CLASSEN, Albrecht, "The Prostitute as Protagonist: The Intriguing Case of Fernando de Rojas's Celestina», capítulo 7 de su Prostitution in Medieval and Early Modern Literature: The Dark Side of Sex and Love in the Premodern Era. Lanham: Lexington Books, 2019, 109-130.

Un análisis de la figura de Celestina y de la importancia de la prostitución en la obra.

2755. COCOZELLA, Peter, "A Catalan "Cobla Sparsa" of the Fifteenth Century: An Icon of Ambivalence in the Misogynistic Background of Celestina, Act I (157-187)", Zeitschrift für Katalanistik 27 (2014), 157-187 [en línea, <http://www.romanistik.uni-freiburg.de/pusch/zfk/27/15_ Cocozzella.pdf $>$, fecha de consulta: 23 de octubre de 2020].

A partir de la "Cobla sparsa de lahor he deslaor» se muestra cómo la alternancia entre el encomio y el vituperio de las mujeres funciona como recurso característico en la literatura inserta dentro del debate sobre las mujeres en el siglo Xv. Para ello, se contextualiza esta alternancia en la tradición poética anterior y se contrasta con el diálogo entre Calisto y Sempronio sobre las mujeres en el primer auto de Celestina y la automodelación de Pere Torroella como representante del antifeminismo literario $y$, a la vez, enamorado.

2756. COCOZZELLA, Peter, "The Exemplarity of the Auto de amores: A Key to the Structure of the Tragicomedia de Calisto y Melibea», European Medieval Drama 11 (2007): 123-135 [en línea, <https://doi.org/10.1484/J. EMD.2.303476>, fecha de consulta: 23 de octubre de 2020]. 
Defiende que los autos centrales de LC (X a XII) emparientan con el "auto de amores». La función reprobatoria de la subtrama de la avaricia de la alcahueta sería una especie de auto de amores inserto en la trama general de $L C$. Su centralidad permite ver los autos anteriores y posteriores como subtramas, la una dedicada a Calisto como víctima cómica del amor y la otra a Melibea como víctima trágica del amor, quedando en el centro Celestina, víctima de su amor por el dinero.

2757. COLINO MARTÍNEZ, José, En torno a "Mollejas el ortelano» de "La Celestina»: Los Mollejas de la Puebla de Montalbán. Toledo: J. Colino, 2016.*

2758. DELGADO GARCÍA, Nitzaira. «Sobre el hilado de Celestina y el cordón de Melibea. Complicidad e intercambio de roles en La Celestina», Trabajo de final de máster, Universidad de Puerto Rico, 2011.

Se intenta demostrar que en $L C$ se produce un intercambio entre los roles de la madre y de la alcahueta. Mientras que Alisa ejerce -involuntariamente o no- de alcahueta al permitir a su hija quedarse a solas con Celestina para que esta pueda informarle del «dolor de muelas» de Calisto, Celestina ocupa el lugar de la madre una vez Melibea le entrega su cordón.

2759. DI CAMILLO, Ottavio, OfRoasted Eggs and Other Issues in the "Celestina", en Docta y sabia Atenea. Studia in honorem Lía Schwartz, ed. Sagrario López Poza et al. La Coruña: Universidade da Coruña, 2019, 249-263 [en línea, <https://doi.org/10.17979/spudc.9788497497046.249>, fecha de consulta: 23 de octubre de 2020].

A partir de algunos indicios textuales de la edición de la traducción italiana de Alphonso Hordognez de Roma (1506) y algunos documentos históricos se propone la existencia de una traducción italiana de la Comedia de Calisto y Melibea de 1501.

2760. ENE, Petre, "El amor cristiano en la Tragicomedia de Fernando de Rojas y en la Segunda Celestina de Feliciano de Silva", Celestinesca 43 (2019): 93-110 [en línea <http://parnaseo.uv.es/Celestinesca/Celestinesca43/04_Ene_Petre.pdf $>$, fecha de consulta: 23 de octubre de 2020].

Mediante la comparación de los conceptos de amor reconocibles en la TCM y en la Segunda Celestina de Feliciano de Silva se aventura que, en el tiempo transcurrido entre ambas obras, se produce una evolución del concepto amoroso desde lo cortés hacia lo cristiano. Esto influye sobre aspectos fundamentales como el propio cortejo amoroso o el comportamiento de los enamorados, pero también sobre la solución matrimonial y, en general, la compatibilidad del amor con los valores cristianos ortodoxos modernos. 
2761. FAJARDO SOTELO, Guillermo Jesús, "Hablillas son”. El discurso autoritativo en La Celestina», Antrópica 6.12 (2020): 175-193 [en línea, $<$ http://www.antropica.com.mx/ojs/index.php/AntropicaRCSH/article/view/230>, fecha de consulta: 23 de octubre de 2020].

Análisis basado en los conceptos bakhtianos de "discurso autoritativo» $y$ "discurso persuasivo interno». La elocuencia y la retórica de Celestina sirven para imponer un modelo vertical de autoridad entre los personajes, pero Sempronio y Pármeno tomarán conciencia de esto y escaparán al control de la alcahueta, lo que provocará su muerte.

2762. FAYE, Thomas, "Proverbes et sentences dans La Celestina: traduction, effets de formes et effets de sens", Les Cahiers de Framespa. Nouveaux champs de l'histoire sociale 10 (2012): s. p. [en línea, <https://doi. org/10.4000/framespa.1393>, fecha de consulta: 23 de octubre de 2020].

A partir de la traducción al francés de Aline Schulman, se analiza el reto que supone la traducción de los refranes de $L C$ debido a la función persuasiva que desempeñan en varios contextos y las estrategias que adoptan los traductores a la hora de enfrentarse a ellos. Se reflexiona igualmente sobre las limitaciones de traducir un texto como LC.

2763. FERNÁNDEZ, Enrique, "Dos ilustraciones y un cuadro: testimonios de la recepción de La Celestina en tres épocas", en Videoactas del I Congreso del CELPYC (4-5 de junio de 2020), ed. Enrique Fernández y Amaranta Saguar. Nueva York: CELPYC, 2020, s. p. [en línea, $<$ https://doi.org/10.47537/celpyc2020.12>, fecha de consulta: 26 de octubre de 2020].

A partir del grabado del auto IX, el del banquete en casa de Celestina, en la edición de la traducción alemana de 1520 se relaciona a Celestina con la representación iconográfica de la Templanza. Por otra parte, se comenta la reinterpretación de la Ortiz, personaje de Gil Blas de Santillana, como un trasunto celestinesco en las ediciones ilustradas de su traducción al español. Finalmente, se analiza el cuadro de Benjamín Palencia La Celestina (1920), en el cual confluyen la maja de Goya y Celestina. Estos tres ejemplos sirven para ver la recepción del personaje de la alcahueta a lo largo de la historia.

2764. FERNÁNDEZ VALLADARES, Mercedes, "Más evidencias bibliográficas para una controversia: el colofón métrico de la Celestina a la luz de dos nuevas ediciones tempranas de la Tragicomedia ("Sevilla 1502")", Criticón 137 (2019): 215-228 [en línea, <https://doi.org/10.4000/criticon.8321>, fecha de consulta: 23 de octubre de 2020].

La reciente localización de dos nuevas ediciones tempranas de la $T C M$, con la fecha de 1502 en el mal llamado "colofón métrico» de 
Proaza, obliga a replantear la controversia bibliográfica, revitalizada en tiempos recientes, sobre el motivo de esa reiteración. La identificación tipobibliográfica del ejemplar hallado en la Biblioteca Nacional de Nápoles, en el contexto de la transmisión post-incunable de la obra, permite descartar que esa fecha sea una errata de los impresores y ayuda a esclarecer la función y los motivos de la que se afianzó como estratagema de contrahechura, prolongada durante las dos primeras décadas del siglo XVI [resumen de la autora].

2765. FRANÇOIS, Jéromine, "La Celestina», un mito literario contemporáneo. Madrid - Frankfurt: Iberoamericana - Vervuert, 2020.

Con el fin de desentrañar el proceso de mitificación conocido por $\mathrm{La}$ Celestina en la época contemporánea, este trabajo analiza treinta reescrituras hispánicas a través de sus tres mitemas comunes: la mediación mágica, la mediación carnal y la tensión social [resumen presente en la página en línea de la editorial].

2766. FRANÇOIS, Jéromine, "Antes del "monstruo" de Rojas. Las "conversiones" de José Martín Recuerda", en Una llama que no cesa: nuevas líneas de investigación en Filología Hispánica, ed. Patricia Barrera Velasco. Madrid: Sial Pigmalión, 2017, 63-80.

La polémica crítica que atañe al protagonismo de la hechicería en el desenlace trágico de La Celestina irrumpe en las recreaciones ficticias a las que ha dado lugar la obra de Rojas desde su publicación. En Las conversiones (1981), José Martín Recuerda propone una precuela del texto tardo-medieval en la que imagina el pasado de la alcahueta para enseñar el proceso mediante el cual la joven Celestina se transformó en la hechicera de Rojas. Este trabajo argumenta sobre el papel que desempeña el motivo hechiceril en este drama como fuente de autonomía e instrumento de rebeldía para la mujer oprimida [resumen de la autora].

2767. FREDRICK, Sharonah, "La Celestina y el colapso del mundo judeoespañol», Raíces: Revista Judía de Cultura 116 (2018), pp. 81-90.

Exploración de posibles elementos judeo-españoles de $L C$, especialmente enfocado a iluminar determinadas citas bíblicas y aspectos característicos de la vida de los judíos españoles.

2768. GARGANO, Antonio, "Sacó mi secreto amor de mi pecho": la confessione amorosa di Melibea (Celestina, auto X)», en La Celestina: ecdotica e interpretazione, ed. Francisco Lobera Serrano. Roma: Bagatto Libri, 2010, 97-120.

Estudio que se publicó anteriormente en Medioevo Romanzo 32 (2008), 116-34, y que se reseñó en el suplemento bibliográfico de esta revista en 2010 . 
2769. GARGANO, Antonio, "Fortuna y mundo sin orden en La Celestina de Fernando de Rojas», en Avatares y perspectivas del medievalismo ibérico, coord. Isabella Tomassetti. San Millán de la Cogolla: Cilengua, 2019, 1363-1382.

Conferencia plenaria que el estudioso pronunció durante el XVII Congreso Internacional de la AHLM y que se incluyó, luego, como segundo capítulo de su libro La ley universal de la vida desorden y modernidad en "La Celestina» de Fernando de Rojas (véase, abajo, núm. 2772).

2770. GARGANO, Antonio, "Modello freudiano e contenuti storici: il codice d'amore cortese-cavalleresco tra La Celestina e il Quijote», SigMa 3 (2019), 411-446 [en línea, <https://doi.org/10.6093/sigma.v0i3.6583>, fecha de consulta: 23 de octubre de 2020].

Análisis del concepto amoroso que rige en $L C$ y en el Quijote desde el punto de vista del Witz (chiste) freudiano. Mientras que en LC las continuas transgresiones del código cortés son fuente de risa e impiden la identificación con los personajes, puesto que ponen en evidencia la naturaleza sexual de sus sentimientos, en el Quijote la cómica falta de correspondencia entre la realidad y el amor idealizado de don Quijote funciona al contrario, propiciando la simpatía por el personaje y dotando de cierta credibilidad a la naturaleza ideal de su amor. Esta no está del todo exenta de la parte física y sensual, pero sí está derivada al personaje de Sancho.

2771. GARGANO, Antonio, La ley universal de la vida desorden y modernidad en "La Celestina" de Fernando de Rojas, Madrid - Frankfurt, Iberoamericana - Vervuert, 2020.

Fruto de más de dos décadas de estudio sobre La Celestina, este volumen propone una lectura de la Tragicomedia como conflicto entre distintos sistemas de valores. En ella la relación entre el texto y el mundo no se valora en términos de mero reflejo, sino que presupone la mediación de un recurso literario, que remite al modelo teórico de "formación de compromiso", según el cual la comicidad actúa como cobertura para la expresión de contenidos o valores no aceptados por la cultura de la época, o bien aceptados o incluso autorizados, pero no por todos los códigos sociales y culturales vigentes en la época [resumen presente en línea en la página de la editorial].

2772. GARCÍA MARSILLA, Juan Vicente et al., "La Celestina (1996)", en Del castillo al plató. Barcelona: Universidad Oberta de Catalunya, 2017, 172-174.

Comentario de la adaptación cinematográfica de Gerardo Vera (1996). 
2773. GARCÍA VALIENTE, Luis, y Antonia MARTÍNEZ PÉREZ, «El uso de la erudición en las continuaciones argumentales de La Celestina», Estudios Románicos 28 (2019), 259-268 [en línea, <https://doi. org/10.6018/ER/377071>, fecha de consulta: 23 de octubre de 2020].

Se compara el uso de citas eruditas en La Segunda Comedia de Celestina de Feliciano de Silva (1534), La Tercera Parte de la Tragicomedia de Celestina de Gaspar Gómez de Toledo (1536) y La Tragicomedia de Lisandro y Roselia de Sancho de Muñón (1542) con su uso en LC original. Esta comparación es tanto cuantitativa como cualitativa.

2774. GERNERT, Folke, "Belleza y deformidad. Melibea y Dulcinea entre tradición y desviación», Studia Aurea 13 (2019), 133-160 [en línea, $<$ https://doi.org/10.5565/rev/studiaaurea.362>, fecha de consulta: 23 de octubre de 2020].

Tanto Melibea como Dulcinea son descritas lo mismo de forma positiva, como mujeres hermosas, que de forma negativa, como mujeres horribles, según el personaje que lo haga. Se analizan estas descripciones desde el punto de vista de la ciencia fisionómica medieval y moderna, así como lo que aportan a la caracterización de ambas mujeres.

2775. GERNERT, Folke, «Philipp II., Celestina und Tlazoteotl: Groteske Körperlichkeit und Hybridisierung in Carlos Fuentes Roman Terra Nostra», en Das Groteske in der Literatur Spaniens und Lateinamerikas, eds. Jörg Türschmann y Matthias Hausmann. Göttingen - Vienna, Vandenhoeck - Ruprecht \& Universität Wien, 2016, 281-305 [en línea, <https://doi.org/10.14220/9783737002318.281>, fecha de consulta: 23 de octubre de 2020].

La novela de Carlos Fuentes es una crítica de los Habsburgo a través de lo grotesco. De entre todas las deformaciones grotescas que se van desgranando, resulta de interés celestinesco la transformación de Celestina en la diosa azteca Tlazoteotl y su posterior convertirse en un ser andrógino que no es ni la diosa, ni la alcahueta ni tan siquiera la mujer debido a su fusión sexual con su amante mexicano. En realidad, toda la caracterización de Celestina en Terra Nostra es un collage no necesariamente integrado de diferentes personajes, incluido el de la alcahueta literaria, y de referencias de la cultura azteca, por lo que en ella confluyen lo hispano y lo mexicano o, mejor dicho, por lo que Celestina ejerce de mediadora entre lo hispano y lo mexicano. Pero, al fusionarse con su amante mexicano en un único ser hermafrodita, se convierte en una metáfora de la identidad cultural mexicana, que es lo hispano y lo americano y ella misma todo a la vez.

2776. GESIOT, Jacopo, "Ancora un plagio in Italia del Tirant to Blanc: la lettera dedicatoria alla Tragicocomedia di Calisto e Melibea (1506)", 
SCRIPTA. Revista Internacional de Literatura i Cultura Medieval i Moderna 14 (2019), 48-56.

Estudio que señala cómo Hordognez, en su carta dedicatoria a Madonna Gentile de Campofregoso, tradujo, adaptó y refundió un pasaje de la introducción del Decamerón de Boccaccio, y diferentes apartados (del prólogo, introducción y cap. 1) del Tirant lo Blanch.

2777. GRILLI, Giuseppe, «Pármeno pícaro, Sosia estudiante de aldea?», en La Celestina: ecdotica e interpretazione, ed. Francisco Lobera Serrano. Roma: Bagatto Libri, 2010, 213- ¿? *

Un estudio con el mismo titulo se recoge en Giuseppe Grilli, La scena originaria: identità e classicità della letteratura spagnola. Roma: Edizioni Nuova Cultura, 2010, 87-110.

2778. GUERRY, François-Xavier, «Du personnage Celestina au type célestinesque. Stéréotypie et innovations dans un cycle littéraire du Siècle d'or (1499-1570)», Crisol 10 (2020), s.p. [en línea, <http://crisol.parisnanterre.fr/index.php/crisol/article/view/208>, fecha de consulta: 23 de octubre de 2020].

Analiza el proceso de tipificación del personaje de Celestina en las continuaciones celestinescas. Además de comentar los rasgos que se intensifican, se descartan, se conservan... se reflexiona sobre cómo se llega a formar un personaje tipo.

2779. HIREL-WOUTS, Sophie, "De la "trotaconventos" à la "buena y sabia maestra": réflexions sur la transmission des savoirs dans La Célestine», en La transmission de savoirs licites et illicites dans le monde hispanique péninsulaire (XIle au XVIIe siècles): Hommage à André Gallego, eds. Teresa Rodríguez y Luis González Fernández. Toulouse: Les Méridiennes, Presses Universitaires du Midi, 2020, 155-169 [en línea, <https://doi.org/10.4000/ books.pumi.32406>, fecha de consulta: 23 de octubre de 2020].

Celestina es, por su saber específico, por su edad y por su relación tutelar hacia los otros personajes, quien tiene más conocimientos que transmitir en $L C$. Los personajes conocen, aceptan y refuerzan su papel de maestra (fuente y transmisora de saber), de lo que Celestina es consciente y se aprovecha para conseguir sus objetivos e imponer su autoridad, sin dudar, además, en manipular, mediatizar, disimular, ocultar o exponer el alcance de su saber ante los otros para lograr sus objetivos. Gracias a esto transmitirá su mensaje incluso en contra de la voluntad de los que la escuchan.

2780. IGLESIAS RECUERO, Silvia, "La construcción del diálogo en $L a$ Celestina: las secuencias de reparación", Estudios Humanísticos. Filo- 
logía 41 (2019), 187-216 [en línea, <http://dx.doi.org/10.18002/ehf. v0i41.5608>, fecha de consulta: 23 de octubre de 2020].

En este trabajo mostramos cómo se adaptan y se utilizan en La Celestina determinadas secuencias típicamente conversacionales y las construcciones o formatos lingüísticos asociados a ellas. En concreto, nos centramos en las secuencias de reparación y estudiamos sus formas lingüísticas y sus funciones conversacionales y textuales para poner de manifiesto cómo contribuyen de manera decisiva a la verosimilitud del diálogo celestinesco [resumen de la autora].

2781. JIMÉNEZ RUIZ, Ana Milagros, «La primera portada celestinesca sevillana: estudio de una parodia iconográfica e iconológica». en $V i$ deoactas del I Congreso del CELPYC (4-5 de junio de 2020), ed. Enrique Fernández y Amaranta Saguar. Nueva York: CELPYC, 2020, s. p. [en línea, <https://doi.org/10.47537/celpyc2020.04>, fecha de consulta: 26 de octubre de 2020].

Análisis del grabado de portada de la edición de la Comedia de Sevilla, Estanislao Polono, 1501. La imagen sería, a la vez, una parodia del amor cortés y una manipulación del esquema compositivo de la iunctio dextrarum que sugiere comicidad.

2782. KEHREN, Timo, «El complejo de Cartago: refracciones fantasmáticas en La Celestina", en Eneas: La trayectoria transatlántica de un mito fundacional, ed. Arturo R. Álvarez Hernández et al. Göttingen: V\&R unipress, 2019, 171-188 [en línea, <https://doi.org/10.14220/9783737 010696.171>, fecha de consulta: 23 de octubre de 2020].

Estudia la referencia al famoso episodio de Dido y Eneas en $L C$ - en el acto VI cuando Calisto alaba la medianera por su trabajo- y lo compara con El burlador de Sevilla, atribuido a Tirso, y la Numancia de Cervantes con el objetivo de demostrar que tras ella se esconde una alusión clara al contexto político en el que nació la obra misma.

2783. KEHREN, Timo, «I. Der Himmel auf Erden: Triumph des Körpers in der Celestina», en Königreich Sodom. Politik der Lust in der spanischen Pikareske. Göttingen: V\&R Unipress - Mainz University Press, 2020, 33-69.

El capítulo forma parte de la tesis de doctorado que el autor presentó en la Universidad Johannes Gutenberg de Maguncia en 2018. El estudio analiza las implicaciones políticas del erotismo picaresco, del que $L C$ representa el punto de partida, en la medida en que el amor físico se impone allí al amor espiritual. El capítulo se divide en tres partes: la primera vuelve sobre el debate genérico, destacando distintos rasgos dramáticos del texto; luego se demuestra que la alcahueta aparece escenificada como "Venus degradada», para la que el amor no es más 
que un negocio; en la tercera parte, finalmente, el autor somete el texto a una lectura propiamente política. En la interpretación que propone, $L C$ es una epopeya que no pudo ser, en la que se asimila el fracaso de la monarquía de los Trastámara [resumen del autor].

2784. KILIAN, Sven Thorsten, "Opening Spaces for the Reading Audience: Fernando de Rojas's Celestina (1499/1502) and Niccolò Machiavelli's Mandragola (1518)», en Dramatic Experience. The Poetics of Drama and the Early Modern Public Sphere(s), ed. Katja Gvozdeva, Tatiana Korneeva y Kirill Ospovat. Leiden: Brill, 2017, 13-34 [en línea, <https://doi.org/10.1163/9789004329768_003>, fecha de consulta: 23 de octubre de 2020].

Contextualiza la recepción de la Mandragola de Machiavelli y LC. Como lectura, $L C$ es consciente de y satisface una variedad de modos de lectura (privada, colectiva, dramatizada), de públicos (homogéneo, heterogéneo) y de objetivos (entretenimiento, didactismo, crítica), y cuenta con las consiguientes diferencias de interpretación. Por su parte, la Mandragola se configura como una pieza teatral más en la línea de la tradición dramática italiana de su tiempo, cuyo valor es estético y de entretenimiento, no moral, ni didáctico, ni político. Pero, como se representa, lo mismo que $L C$, está abierta a nuevos públicos y, por lo tanto, sujeta a nuevas interpretaciones.

2785. KOWALSKY, Lisa Marie, "Ilustraciones interpretativas: espacios, repetición de imágenes y animales en cien años de La Celestina: ediciones españolas de 1500 a 1600", Trabajo de fin de máster, Calgary, University of Calgary, 2018 [en línea, <http://dx.doi.org/10.11575/ PRISM/32911>, fecha de consulta: 23 de octubre de 2020].

Análisis de los grabados de catorce ediciones ilustradas de $L C$ entre 1500 y 1600. Examina su función como apoyo visual del texto y estudia su reutilización, evolución y modificación a lo largo del tiempo y el espacio, y la inclusión de animales. También estudia cómo contribuyen a explicar tanto los valores de la época sobre el espacio, la interacción personal, los eventos contemporáneos... como la postura ante los propios personajes y su comportamiento. Finalmente, analiza los casos en los que los grabados entran en conflicto con el texto.

2786. LACARRA, María Jesús, «La tradición iconográfica de la Tragicomedia de Calisto y Melibea (Zaragoza: Pedro Bernuz y Bartolomé de Nájera, 1545)", en Avatares y perspectivas del medievalismo ibérico, ed. Isabella Tomassetti. San Millán de la Cogolla: Cilengua, 2019, 237-250.

El análisis detallado de los grabados de la edición de Zaragoza, Pedro Bernuz y Bartolomé de Nájera, 1545 lleva a la autora a concluir que 
son de gran originalidad y están directamente derivados de una lectura atenta del texto.

2787. LASSERRE DEMPURE, Odile, "Écrire le personnage, dire l'humain: La Celestina (1499-1502) de rupture en rupture jusqu'aux confins de la modernité», Babel. Littératures plurielles 26 (2012), 17-44 [en línea, $<$ https://doi.org/10.4000/babel.2549>, fecha de consulta: 23 de octubre de 2020].

Repaso de los motivos que contribuyen a la caracterización de los personajes de $L C$. Plantea el conflicto entre lo que responde al tipo y a la tradición y lo que se puede considerar una caracterización más individual y personal. Valora también cuánto de tipo y cuánto de ruptura hay en los diferentes personajes pero, en cualquier caso, lo que motiva y lo que provoca dicha ruptura es una actitud hedonista ante la vida.

2788. LÁZARO REBOLL, Antonio, "Epicentro de La Celestina», Crónicas: Revista Trimestral de Carácter Cultural de La Puebla de Montalbán 40 (2017), 23-23. *

2789. LEROUX, Xavier, «Du texte mis entre parenthèses au texte dit à part. nouvelles remarques sur l'aparté dans La Celestina de Fernando de Rojas», Babel. Littératures plurielles 22 (2010), 75-98 [en línea, <https://doi. org/10.4000/babel.220>, fecha de consulta: 23 de octubre de 2020].

Estudia la representación gráfica del aparte en distintas ediciones de $L C$. Destaca su importancia para poner de manifiesto tanto la ambigüedad como la ironía, pero también cómo precisamente el efecto cómico o relativizador de esas ambigüedad e ironía hace que perdamos de vista la percepción de lo que está sucediendo de la persona a la que no está destinada el aparte, mediatizando nuestra recepción de la situación.

2790. LIHANI, John, "Spanish Urban Life in the Late Fifteenth Century as Seen in Celestina», en Spanish Literature: A Collection of Essays. From Origins to 1700, eds. David Foster et al. New York: Routledge, 2000, vol. 2, pp. 159-166 [en línea, <https://www.taylorfrancis.com/ books/e/9780203825075/chapters/10.4324/9780203825075-13>, fecha de consulta: 23 de octubre de 2020].

Reimpresión del artículo que apareció en Celestinesca 11.2 (1987).

2791. LOBERA SERRANO, Francisco, «La transmisión del texto de La Celestina entre 1520 y 1535", en La Celestina: ecdotica e interpretazione, ed. Francisco Lobera Serrano. Roma: Bagatto Libri, 2010, 61-96. *

2792. LÓPEZ RODRÍGUEZ, Irene, «La Celestina (1499) cinco siglos más tarde: ecos celestinescos en Tiempo de Silencio (1962)", Celestinesca 43 (2019), 111-130 [en línea, <http://parnaseo.uv.es/Celestinesca/Celes- 
tinesca43/05_Lopez-Rodriguez_Irene.pdf $>$, fecha de consulta: 23 de octubre de 2020].

El personaje de Doña Luisa de Tiempo de silencio (1962) tiene ecos notables de Celestina, tanto a nivel físico como psicológico, pero también desde el punto de vista de sus múltiples oficios, sus rasgos infernales, la ubicación marginal de su casa, su trayectoria personal y las relaciones que establecen con otros personajes. En ambas obras, el personaje de la prostituta vieja sirve para exponer los conflictos morales y sociales del momento.

2793. MANCHA, María Valeria, «Melibea y Adela: una reescritura lorquiana de la rebeldía femenina ante la violencia simbólica patriarcal», Boletín GEC 24 (2019), 96-111 [en línea, <http://revistas.uncu.edu.ar/ ojs3/index.php/boletingec/article/view/2290>, fecha de consulta: 23 de octubre de 2020].

Melibea y Adela se erigen como mujeres rebeldes que quieren gozar de su amor sin la presión ni el control de sus padres ni de la sociedad. Ambas se oponen al papel asignado a la mujer en las sociedades de sus respectivas épocas, por lo que otros personajes femeninos reaccionan con reparo o directamente con rechazo ante ellas.

2794. MARTÍ CALOCA, Ivette, "Vencido me tiene el dulçor de tu suave canto": Melibea y la imagen de la sirena", Celestinesca 43 (2019): 131-140 [en línea, <http://parnaseo.uv.es/Celestinesca/Celestinesca43/06_Marti_Yvette.pdf $>$, fecha de consulta: 23 de octubre de 2020].

Aunque sea Areúsa la que en el auto VII sea comparada con una sirena, el verdadero monstruo de $L C$ es Melibea, pues todas las personas involucradas en su relación con Calisto sufrirán un destino terrible, similar al de las víctimas de los seres mitológicos. Se desgranan algunas coincidencias entre las caracterizaciones de Melibea y la de las sirenas.

2795. MARTí CALOCA, Ivette, «"La víbora no merece ser culpada por la ponzoña que tiene": Melibea y la pastora Marcela», en Videoactas del I Congreso del CELPYC (4-5 de junio de 2020), ed. Enrique Fernández y Amaranta Saguar. Nueva York: CELPYC, 2020, s. p. [en línea, $<$ https://doi.org/10.47537/celpyc2020.05>, fecha de consulta: 26 de octubre de 2020].

Comparación entre las figuras de la pastora Marcela y la de Melibea.

2796. MIRAGLIOTTA, Elisa, "Transcripción paleográfica y análisis de la segunda traducción italiana de la tragicomedia La Celestina [Biblioteca Nazionale Marciana DRAMM 0123]", Trabajo de fin de máster, Venecia, Università Ca'Foscari, 2017 [en línea, <http://dspace.unive.it/ handle/10579/9703>, fecha de consulta: 23 de octubre de 2020]. 
Transcripción y análisis de la edición — que no la traducción — de Girolamo Claricio de la versión italiana de LC, impresa en Milán por Zanotto da Castione (Giovanni Castiglione) en 1514 para los hermanos Da Legnano. Partiendo de la base de que se trata de una traducción diferente a la de Alphonso Hordognez, establece una comparación indirecta, basada en estudios previos y no en una comparación directa de ambos textos, entre esta edición milanesa de 1514 y la anterior de Roma, [Eucario Silber], 1506, encontrando únicamente variantes formales, gráficas, dialectales y reformulaciones mínimas perfectamente acordes con un proceso de edición.

2797. MORENO MORENO, Juan, "La Celestina en cuerpo y alma: conocimientos médicos en la Tragicomedia de Fernando de Rojas», Trabajo de fin de máster, Ljubljana, Univerza v Ljubljani, 2019 [en línea, $<$ https://repozitorij.uni-lj.si/IzpisGradiva.php?id=107700>, fecha de consulta: 23 de octubre de 2020].

Repaso de los elementos de $L C$ atribuibles a influencia de la ciencia médica de su época: los ingredientes farmacéuticos del laboratorio de Celestina, los conocimientos de medicina femenina de la alcahueta y la aegritudo amoris.

2798. MUÑIZ MUÑIZ, María de las Nieves, «Dal Tirant lo Blanc alla Celestina", en La "descriptio puellae» nel Rinascimento: percorsi del topos fra Italia e Spagna con un'appendice sul "locus amoenus». Firenze: Franco Cesati editore, 2018, 132-150.

Estudio de la descriptio puellae y de sus fuentes en el Tirant lo Blanc (con particular atención al personaje de Carmesina) y LC (en la muy conocida descripción que hace Calisto de Melibea).

2899. OROBITG, Christine, "Rire et mélancolie dans La Celestina", Babel. Littératures plurielles 22 (2010): 31-52 [en línea, <https://doi. org/10.4000/babel.207>, fecha de consulta: 23 de octubre de 2020].

Análisis del personaje de Celestina a partir de las teorías científicas contemporáneas sobre el humor melancólico y la representación pictórica de la melancolía. En esta la tensión y la alternancia entre lo alegre y lo melancólico es un tema recurrente, como en la caracterización de la alcahueta.

2800. OTOCH, Janaína Nagata, "Trama de olhares: notas sobre a representação da Celestina na obra de Pablo Picasso", en Os silêncios na História da Arte (XII Encontro de História da Arte), ed. Alexandre Pedro de Medeiros. Campinas: Unicamp, 2017, 336-348 [en línea, <https:// www.ifch.unicamp.br/eha/atas/2017/Janaina \%20Nagata \%20Otoch. pdf $>$, fecha de consulta: 23 de octubre de 2020]. 
Repaso a la presencia del personaje de Celestina en distintos momentos de la obra de Picasso: la juventud, donde más recurrente es, y su vejez, donde aparece en la famosa serie de grabados de 1968 y asociada con temas sexuales. Sin embargo, nunca pinta propiamente escenas del texto, sino que más bien se inserta en la tradición pictórica de cuadros que representan escenas de prostitución y tercería. Se relaciona este tipo de temática y la presencia de la alcahueta con un acercamiento voyeurístico a la prostitución.

2801. PACCAGNELLA, Ivano, "Generi di traduzione, selezioni editoriali, scelte linguistiche», en "Fedeli, diligenti, chiari e dotti». Traduttori e traduzioni nel Rinascimento, ed. Elisa Gregori. Padova: CLEUP, 2016, 43-66.

Resulta de interés celestinesco la sección 3 , donde con motivo de la traducción de obras teatrales en Italia comenta la tradición de la traducción italiana de LC de Alphonso Hordognez y su función como texto base de las traducciones alemanas y francesas de LC (y puede que de la primera versión inglesa de Mabbe).

2802. PACCAGNELLA, Ivano, "Fortuna veneziana della Celestina», en Lingua, letteratura e umanità. Studi offerti dagli amici ad Antonio Daniele, ed. Vittorio Fomentin et al. Padova: CLEUP, 2016, 155-165.

Repaso de la tradición editorial de $L C$ en Italia. Distingue las ediciones milanesas de las venecianas. Atribuye la sucesión de ediciones venecianas a la tradición teatral de la ciudad. Prosigue comentando las entradas relacionadas con $L C$ del repertorio de textos teatrales de Marin Sanudo como prueba de la popularidad de $L C$ en Italia y pasa a hablar de las traducciones alemana y francesa derivadas de la traducción italiana.

2803. PAOLINI, Devid, "Celestina: Documento bibliográfico (suplemento número 40)», Celestinesca 42 (2018): 305-316 [en línea, <http://parnaseo.uv.es/Celestinesca/Celestinesca42/14_Suplemento_Bibliografico_40.pdf $>$, fecha de consulta: 23 de octubre de 2020].

En el suplemento bibliográfico de 2018 se han agregado 60 entradas que desde 1985 suman ya 2601.

2804. PONTÓN, Gonzalo, «Parecidos de familia (de la Comedia a la Tragicomedia)", en La Celestina: ecdotica e interpretazione, ed. Francisco Lobera Serrano. Roma, Bagatto Libri, 2010, 43-60. *

2805. PRIETO DE LA IGLESIA, María Remedios, y Antonio SÁNCHEZ SÁNCHEZ-SERRANO, "Correcciones en la Tragicomedia suscitadas por críticas a la Comedia. Construcción textual de la Comedia inherente a prácticas tradicionales y el apoyo de Cisneros», Celestinesca 43 (2019): 141176 [en línea, <http://parnaseo.uv.es/Celestinesca/Celestinesca43/07_ Prieto_Remedios.pdf $>$, fecha de consulta: 23 de octubre de 2020]. 
Análisis de algunos cambios introducidos por la Tragicomedia respecto a la Comedia, que se interpretan como correcciones que intentan subsanar errores e incoherencias introducidos en el texto de la Comedia al reescribir una Comedia anterior a la que conocemos, manuscrita y de final feliz. Las sucesivas reescrituras de esta Comedia primitiva están en el origen de muchos de los loci critici interpretativos de hoy día, pues derivan de incompatibilidades entre la concepción original de la obra como comedia al modo de las humanísticas y la obra moralizante que conocemos hoy día.

2806. RIO, Aurelia. De "La Celestina" a la "Farsa de la Costanza": la automodelación como lugar común. Madrid: Editorial Verbum, 2019.

En este libro se estudia La Tragicomedia de Calisto y Melibea, única obra conocida de Fernando de Rojas, y la recién descubierta Farsa de la Costanza de Cristóbal de Castillejo, a la luz del concepto de la auto-modelación. En este sentido, se conecta este principio clave del Nuevo Historicismo con los estudios de la performance y el realismo grotesco. Temas como los efectos del establecimiento de la Inquisición en la vida de los conversos; el papel que juega la posible ascendencia judía de Rojas en su auto-configuración social y en su obra; el impacto de la vida áulica y la condición de monje en la obra de Castillejo, específicamente en la Farsa; las concomitancias entre La Celestina y la Farsa de la Costan$z a$, entre otros, constituyen elementos fundamentales, que permiten examinar los diversos aspectos sociales e históricos de dichas obras a través del prisma de la auto-modelación, la performance y el realismo grotesco [resumen presente en la página en línea de la editorial].

2807. ROJAS, Fernando de, La Celestina, texto adaptado al castellano moderno por Antonio Gálvez Alcaide. Barcelona: Ediciones Morfeo, 2019.*

2808. ROMERO, Loreto, The Gaze of Celestina: Celestina's Anamorphosis and the Sixteenth-Century Reader, Tesis doctoral, Charlottesville, University of Virginia, 2019 [en línea, <https://doi.org/10.18130/v3qx5t-3043>, fecha de consulta: 23 de octubre de 2020].

Análisis del éxito de $L C$ en el siglo xvi desde el punto de vista de la anamorfosis como técnica visual y literaria para forzar la perspectiva. El texto de $L C$ manipula la manera en la que el lector recibe el texto de la misma forma en la que la anamorfosis pictórica obliga a que la apreciación de los detalles ocurra solo desde determinado ángulo o con la intervención de determinado medio. Los sentidos en $L C$ no siempre son visibles a primera vista, sino que son determinados principios ideológicos y hábitos de pensamiento vinculados al momento histórico y al lector los que permiten percibirlos. Esto hace que, a medida que cambian las circunstancias socio-históricas y cultural-intelec- 
tuales, y con ello el público lector, el significado de LC tenga que ser repensado y renegociado [adaptación del resumen de la autora].

2809. ROMERO, Loreto, "El cuerpo en pedazos: Violencia, erotismo y fragmentación en las ilustraciones de la "Tragicomedia de Calisto y Melibea», en Videoactas del I Congreso del CELPYC (4-5 de junio de 2020), ed. Enrique Fernández y Amaranta Saguar. Nueva York: CELPYC, 2020 , s. p. [en línea, <https://doi.org/10.47537/celpyc2020.10>, fecha de consulta: 26 de octubre de 2020].

Análisis de la relación entre texto e imagen en las ediciones ilustradas de LC. La fragmentación del texto, de las escenas, del espacio y, finalmente, de los personajes que se ve en los grabados de las muertes es una forma de violencia visual que influye sobre la recepción de la obra.

2810. RUBIO PACHO, Carlos, "Para yo dar [...] congrua y saluzable melezina: Celestina, ¿bruja o médica?», en Mujeres en la hoguera: representaciones culturales y literarias de la figura de la bruja, ed. Marina Fé. México: Universidad Autónoma de México, 2014, 109-118.

Celestina encaja en el papel de médico pues, por un lado, desempeña esa función en su papel de fabricante de remedios y de médico de mujeres y de niños; por otro, se enfrenta a un caso de amor hereos, que es una enfermedad, y lo hace conociendo sus síntomas y su tratamiento.

2811. RUIZ MONEVA, Maria Angeles, "Foreshadowing in Ruano de la Haza's twenty-first century adaptation of Rojas' Celestina», Celestinesca 43 (2019), 177-202 [en línea, <http://parnaseo.uv.es/Celestinesca/ Celestinesca43/08_Ruiz-Moneva_MA.pdf $>$, fecha de consulta: 23 de octubre de 2020].

Comentario de la adaptación escénica de LC de Ruano de la Haza (2004). Al ubicar el planto de Pleberio al principio y al final de la misma, se crea una estructura circular que refuerza la tendencia a la prolepsis y a la prefiguración (irónica o no) de $L C$.

2812. RUIZ-MONEVA, María Ángeles, "A Spanish Contribution to the Development of the English Interlude: From Rojas' La Celestina to Rastell's Calisto and Melebea», Romance Quarterly 67.2 (2020), 101-118 [en línea, <https://doi.org/10.1080/08831157.2020.1732748>, fecha de consulta: 23 de octubre de 2020].

La adaptación escénica de LC conocida como Interlude of Calisto and Melibea (ca. 1525) bebe del teatro renacentista inglés contemporáneo, pero también resulta evidente en ella el origen español del modelo. Se analiza el proceso según el cual la obra original es adaptada al género particular del interlude inglés. 
2813. SABEC, Maja, "Crueldad - piedad - concupiscencia: el sincretismo del discurso amoroso en la literatura castellana del siglo XV», Colindancias - Revista de la Red de Hispanistas de Europa Central 10 (2020): 65-80 [en línea, <https://colindancias.uvt.ro/index.php/colindancias/article/ view/250>, fecha de consulta: 23 de octubre de 2020].

Análisis del concepto de misericordia (pietas) en el contexto cristiano y en el de la variante del amor cortés típica del siglo xv hispano. Aunque la misericordia que el enamorado espera de la dama, en un principio, debería permanecer dentro de lo aceptable por la moral cristiana, lo cierto es que todas las referencias a la misericordia amorosa en $L C$ están cargadas de dobles sentidos lascivos, tanto por la parte masculina como por la parte femenina.

2814. SAGUAR GARCÍA, Amaranta y Devid PAOLINI, «Celestina: Documento bibliográfico (suplemento número 41)», Celestinesca 43 (2019): 305-347 [en línea, <http://parnaseo.uv.es/Celestinesca/Celestinesca43/17_Suplemento_Bibliografico.pdf $>$, fecha de consulta: 13 de noviembre de 2020].

En el último suplemento bibliográfico se han añadido 130 entradas que desde 1985 suman ya 2732 .

2815. SAGUAR GARCÍA, Amaranta, «¿Un programa iconográfico original? Modelos alemanes para los tacos de la edición Zaragoza, en la oficina de Jorge Coci a costa de Pedro Bernuz y Bartolomé de Nájera, 17 de junio de 1545, de Celestina», en Videoactas del I Congreso del CELPYC (4-5 de junio de 2020), ed. Enrique Fernández y Amaranta Saguar. Nueva York: CELPYC, 2020, s. p. [en línea, <https://doi.org/10.47537/ celpyc2020.11>, fecha de consulta: 26 de octubre de 2020].

Se postula que una parte de los grabados de la edición de la Tragicomedia de Zaragoza, Pedro Bernuz y Bartolomé de Nájera, 1545 está directamente basada en los grabados de la edición de la traducción alemana de Augsburgo, Heinrich Steiner, 1534.

2816. SÁNCHEZ SAGRADO, Lucas, "La piedad filial en La Celestina: una interpretación desde la perspectiva del confucianismo», Celestinesca 43 (2019), 203-220 [en línea, <http://parnaseo.uv.es/Celestinesca/Celestinesca43/09_Sanchez_Lucas.pdf>, fecha de consulta: 23 de octubre de 2020].

Aplicación de los principios del confucianismo a las relaciones paterno-filiales de LC. Se destaca la coincidencia entre las sociedades chinas e hispana en lo que a la preocupación por la relación entre padres e hijos se refiere, en particular, el respeto y cariño debidos por los hijos hacia sus progenitores o piedad filial. Esta se extiende más allá de las relaciones sanguíneas y también explica las dinámicas entre los criados y las prostitutas y Celestina, ya que actúa como madre de estos. 
2817. SANTIAGO, Igor, y Fernando de SÁ OLIVEIRA JÚNIOR, "Puta velha" e alcoviteira: a representação da mulher feiticeira na obra $L a$ Celestina de Fernando de Rojas (1520)", en I Encontro Internacional de História do Sertão: A educação e os desafios contemporâneos (25-27 setembro 2019). Delmiro Gouveia: Universidade Federal de Alagoas, 2020, s.p. [en línea, <https://doity.com.br/anais/i-eihs/trabalho/149604>, fecha de consulta: 23 de octubre de 2020].

Análisis de la caracterización de las mujeres acusadas de practicar la hechicería en el siglo XVI a partir del personaje de Celestina en el Libro de Calisito y Melibea y la puta vieja Celestina (1520): mujer de edad, sin marido, en mala situación económica, con trato con lo sobrenatural pero también con lo más mundano a través de sus muchos oficios, incluido el de prostituta. En este retrato se produce, además, una ruptura con la caracterización medieval de las hechiceras, en cuanto que Celestina practica su arte en la ciudad y no tiene relación con la naturaleza, sino con los bajos fondos y, en general, el tejido urbano.

2818. SANTIAGO ÁLVAREZ, Cándido, "Cotejo de animales invertebrados en La Celestina y La Lozana andaluza», Revista de Folklore 439 (2018): 37-50 [en línea, <http://www.cervantesvirtual.com/obra/ cotejo-de-animales-invertebrados-en-la-celestina-y-la-lozana-andaluza-970175>, fecha de consulta: 23 de octubre de 2020].

Comentario de la función desempeñada por los animales invertebrados en los símiles y las metonimias de LC y la Lozana. Comentario también de los usos no figurados, cuando la mención de los invertebrados responde a la realidad de la situación.

2819. SERÉS, Guillermo, "La interpretatio y otros recursos afines en $\mathrm{La} C e$ lestina», en La Celestina: ecdotica e interpretazione, ed. Francisco Lobera Serrano. Roma: Bagatto Libri, 2010, 195-212. *

2820. SEVERIN, Dorothy Sherman, "Celestina and the Magical Empowerment of Women», en Spanish Literature: A Collection of Essays. From Origins to 1700, eds. David Foster et al. New York: Routledge, 2000, vol. 2, 167-187. [en línea, <https://www.taylorfrancis.com/ books/e/9780203825075/chapters/10.4324/9780203825075-14>, fecha de consulta: 15 de septiembre de 2019].

Recoge el artículo publicado en Celestinesca 17.2 (1993).

2821. SNOW, Joseph T., "Cómo los autores de Celestina concibieron el personaje de Areúsa», Celestinesca 43 (2019): 221-240 [en línea, $<$ http://parnaseo.uv.es/Celestinesca/Celestinesca43/10_Snow_Joseph.pdf $>$, fecha de consulta: 23 de octubre de 2020]. 
Reconsideración del personaje de Areúsa. Se defiende que, lejos de ser un personaje mal caracterizado o contradictorio, está perfectamente construido en cada una de sus apariciones. Se perfila como una mujer independiente de gran carácter, pero con los errores, las dudas y las incoherencias no de un personaje mal constituido, sino de una personalidad compleja, que la aleja del estereotipo de la prostituta.

2822. SNOW, Joseph T., "Clothing in Celestina: How it Advances the Plot», Miríada Hispánica 17 (2019), 97-110 [en línea, <http://www.miriadahispanica.com/revista/75d6ff3786c2a19f63286774b2f903881efa 79c5.pdf $>$, fecha de consulta: 23 de octubre de 2020].

En este análisis la ropa abarca tanto las prendas de vestir (el manto de Celestina) como los adornos y complementos (la cadena de Calisto, el cordón de Melibea) y los materiales con los que se fabrican (el hilado). Todos estos marcan un paso adelante en la trama, ejerciendo como fuerzas motrices de los personajes o como desencadenantes de las situaciones, según el momento.

2823. TARAVACCI, Pietro, "La Celestina come "contienda cortés"», Studi Ispanici (1983): 9-35.

Tras una caracterización del amor cortés español y un repaso a la literatura amorosa en el entorno de $L C$, se procede a contextualizar los rasgos corteses de $L C$, destacando las desviaciones del modelo y las ambigüedades de muchas de las situaciones más característicamente corteses. Se concluye que Rojas busca teatralizar el amor cortés literario de su tiempo pero, para hacerlo, lo saca de su espacio convencional y lo traslada a una realidad que es toda "batalla y contienda", de donde vienen en realidad las aparentes contradicciones y ambigüedades.

2824. TARAVACCI, Pietro, "Riscrittura e innovazione nella Égloga de la Tragicomedia de Calisto y Melibea di Pedro Manuel Ximénez de Urrea», Quaderni di Filologia Romanza della Facoltà di Lettere e Filosofia dell'Università di Bologna 10 (1993): 171-208.

Análisis de las divergencias de la Égloga de la Tragicomedia de Calisto y Melibea respecto a su modelo, tanto las que pueden atribuirse al cambio de género como a las que responden a un deseo de innovación, de interpretación o de dramatización e intensificación. Aunque el texto sea fiel al original, las modificaciones mínimas y la selección a las que es sometido bastan para que no se pueda considerar una reescritura servil. Se acompaña de una edición del texto.

2825. TOMA, Laura Monica. "Literary Masterpieces Create Their Lineage": Awakening of Conscience in La Celestina: Comedia o Tragicomedia de Calisto y Melibea». Diálogos 37 (2020): 114-127. 
Se analiza el efecto de la progresiva desaparición de la visión del mundo medieval en el paso al siglo XVI, tanto sobre el individuo como sobre los valores sociales, morales y económicos. Para ello se presta especial atención a la notable conciencia que los personajes de $L C$ tienen de sí mismos y a su individualismo, especialmente los personajes bajos, cuya autoconciencia subvierte lo esperable del orden social de la época [adaptación del resumen de la autora]

2826. UGARTE I BALLESTER, Xus, y Joan FONTANA TOUS, "Pa can vieyu nun hai cus-cus". Los refranes de La Celestina en asturiano", Archivum: Revista de la Facultad de Filología 69 (2019): 343-420 [en línea, $<$ https://doi.org/10.17811/arc.0.2019.343-420>, fecha de consulta: 23 de octubre de 2020 ].

A partir del examen de los refranes en la traducción de Pablo Suárez García de $L C$ al asturiano se analizan las diferentes estrategias del traductor a la hora de naturalizar el texto. Además, se incluye una tabla con el equivalente asturiano de los refranes celestinescos del repertorio de José Gella Iturriaga (1977).

2827. VELASCO RAMOS, Pedro, "Areúsa: la otra pupila de La Celestina», Crónicas: revista trimestral de carácter cultural de La Puebla de Montalbán 26 (2013), 8-12. *

2828. VELASCO RAMOS, Pedro, «Nuevos hallazgos sobre los escenarios pueblanos de La Celestina», Crónicas: Revista Trimestral de Carácter Cultural de La Puebla de Montalbán 40 (2017), 30-35. *

2829. VILLALOBOS GRAILLET, José Eduardo, «La Celestina en la Transición. Censura, polémica e interpretación de la recreación telefílmica de Juan Guerrero Zamora», Celestinesca 43 (2019): 241-286 [en línea, $<$ http://parnaseo.uv.es/Celestinesca/Celestinesca43/11_Villalobos_ Jose.pdf $>$, fecha de consulta: 23 de octubre de 2020].

Revisión de las censuras, las críticas y las polémicas en torno a la adaptación televisiva de $L C$ de Juan Guerrero Zamora para TVE, emitida finalmente en 1983. Comienza con un análisis de la censura franquista del primer guión, destinado al cine y no a la televisión, y todos los cambios a los que fue sometido hasta conseguir la aprobación oficial en 1965, aunque no se llega a rodar. Continúa con una descripción de los problemas, los cambios y las polémicas que marcaron el paso a la versión televisiva, así como de las críticas con que la mini-serie de tres capítulos fue recibida. Finaliza con un análisis-defensa de la propuesta interpretativa de Guerrero Zamora.

2830. VON PRELLWITZ, Norbert, "Postille a "Sacó mi secreto amor de mi pecho': la confessione amorosa di Melibea (Celestina, auto X)", di 
Antonio Gargano», en La Celestina: ecdotica e interpretazione, ed. Francisco Lobera Serrano. Roma: Bagatto Libri, 2010, 121-124. *

2831. VRIES, Henk de, La Celestina por dentro: Una exégesis numerológica de la "Comedia de Calisto y Melibea". Madrid - Frankfurt, Iberoamericana - Vervuert, 2020.

El sentido arcano del mensaje poético de la Tragicomedia de Calisto y Melibea ha quedado siempre revestido por un halo de misterio para sus lectores. Henk de Vries consiguió descubrir en el acróstico de los versos introductorios al drama, el famoso "El bachjler Fernando de Roias acabó la Comedia de Calysto y Melybea e fve nascjdo en la Puebla de Montalván", la clave para una exégesis de la composición numerológico-simbólica de la obra. Precedido de un análisis preliminar sobre principios numerológicos y estructuras numéricas en otras obras medievales, este pormenorizado estudio de la organización oculta de La Celestina permite a De Vries presentar una originalísima contribución al debate sobre algunas de las cuestiones más controvertidas en la crítica celestinesca. ¿Era Fernando de Rojas un cristiano nuevo judaizante, adversario de la Iglesia, o más bien un creyente ortodoxo que, inspirado en ideales sociales, pretendía dirigir una severa crítica contra la relajada moral de ciertas clases ociosas en la sociedad de su tiempo? [resumen presente en la página en línea de la editorial]

2832. WESTERVELD, Govert, Researches on the Mysterious Aragonese Author of "La Celestina", autoeditado, Lulu.com, 2016. *

2833. XIA, Tian, "Estudio comparativo entre Xi Xiang Ji y La Celestina». Tesis doctoral, Santiago de Compostela, Universidade de Santiago de Compostela, 2018.

2834. YANG, Xiao, «El amor-pasión en las dos protagonistas de La Celestina y de la Historia del ala oeste de Wang Shifu», Boletín de la Real Academia Española 99.320 (2020), 917-963 [en línea, <http://revistas.rae. es/brae/article/view/199>, fecha de consulta: 23 de octubre de 2020].

Estudio comparativo de las protagonistas de LC e Historia del ala oeste respecto al amor apasionado que anuncia el título, pero también otros aspectos de los personajes como el libre albedrío, la libertad de elección, la sensualidad, y los tópicos de la doblez y la lujuria femeninas. Ambas heroínas comparten ideas proto-feministas sobre su rol en la sociedad y en el amor, y aspiran a mayor libertad en ambos. 